\title{
CAPITAL CULTURAL, LETRAMENTO E FÁBRICAS DE CULTURA EM SÃO PAULO
}

\author{
Heloisa Marcassa MONTEIRO ${ }^{\mathrm{i}}$ \\ Leda Maria de Oliveira RODRIGUES ${ }^{\text {ii }}$
}

\begin{abstract}
RESUMO
Este artigo tem o objetivo de registrar os resultados obtidos na pesquisa de Dissertação de Mestrado do Programa de Educação: História, Política, Sociedade, intitulada Capital cultural e letramento: participantes do Programa Fábricas de Cultura em São Paulo, de Heloisa Marcassa Monteiro. A pesquisa foi construída a partir de um referencial teórico pautado nas ideias de Pierre Bourdieu, Bernard Lahire e na Teoria do Letramento. A proposta foi compreender o Projeto Espetáculo da Fábrica de Cultura do Jardim São Luís, por um lado, como atividade de contraturno escolar e, por outro, como um espaço promotor de capital cultural. Ao desenvolver o conceito de capital cultural e sua incorporação pelas atividades do Projeto, analisou-se, também, a contribuição do aumento do volume desse capital para o letramento dos participantes. A pesquisa estabeleceu categorias de análise para compreender a incorporação do capital cultural como forma de desenvolver habilidades e competências definidas como importantes ao letramento. Pretende-se, assim, expandir as conclusões que possibilitaram afirmar a hipótese levantada durante a referida dissertação: o Projeto Espetáculo, do Programa Fábricas de Cultura, da Secretaria da Cultura do Governo do Estado de São Paulo, pode contribuir à superação dos déficits originários do capital cultural de jovens estudantes e, como consequência, promover melhoras no grau de letramento dos participantes.
\end{abstract}

PALAVRAS-CHAVE: Capital cultural; Letramento; Sucesso escolar; Atividades culturais; Políticas públicas.

\section{CULTURAL CAPITAL, LITERACY AND CULTURE FACTORIES IN SÃO PAULO}

\begin{abstract}
This paper aims to record the results obtained in the Master's Dissertation research of the Education Program: History, Policy, Society, entitled Cultural Capital and Literacy: participants of the Cultural Factories program in São Paulo, conducted by Heloisa Marcassa Monteiro. The research was built from a theoretical framework based on the ideas of Pierre Bourdieu, Bernard Lahire and the Theory of Literacy. The proposal was to understand the Theatrical Project of the 'Jardim São Luís' Cultural Factory (Projeto Espetáculo da Fábrica de Cultura do Jardim São Luís), on the one hand, as an extrahour school work activity and, on the other hand, as a cultural capital promoter space. In developing

\footnotetext{
${ }^{\text {i }}$ Psicóloga com Mestrado em Educação: História, Política, Sociedade pela Pontifícia Universidade Católica de São Paulo (PUC-SP). Atuação profissional como Psicoterapeuta Clínica e Educadora no ensino fundamental. Email: heloisammonteiro@gmail.com.

${ }^{i i}$ Doutora em Psicologia Social pela Universidade de São Paulo (USP). Pós-doc em Psicologia Social na École des Hautes Études en Sciences Sociales, Paris, França. Docente do Programa de Estudos Pós-graduados em Educação: História, Política, Sociedade da PUC-SP. E-mail: ledamor.puc@ gmail.com.
} 
the concept of cultural capital and its incorporation into the activities of the Project, the contribution of increased cultural capital towards literacy of the participants was also analyzed. The research established analysis categories to understand the incorporation of cultural capital as a way to develop skills and competences defined as important to literacy. This article intends to expand the conclusions that made to affirm the hypothesis raised during the dissertation mentioned possible: the Theatrical Project of the Cultural Factory Program, of the Cultural Secretariat of the Government of the State of São Paulo, Brazil, can contribute to overcoming deficits arising from the cultural capital of young students and, as a consequence, to promote improvements in the degree of literacy of the participants.

KEYWORDS: Cultural capital; Literacy; School success; Cultural activities; Public policy.

\title{
CAPITAL CULTURAL, LETRAS Y FÁBRICAS DE CULTURA EN SÃO PAULO
}

\begin{abstract}
RESUMEN
Este artículo tiene el objetivo de registrar los resultados obtenidos en la investigación de Disertación de Maestría del Programa de Educación: Historia, Política, Sociedad, titulada "Capital cultural y letramento - participantes del Programa Fábricas de Cultura en São Paulo", de Heloisa Marcassa Monteiro. La referida investigación fue construida a partir de un referencial teórico pautado en las ideas de Pierre Bourdieu, Bernard Lahire y en la Teoría del Letramento, y tuvo como propuesta comprender el Proyecto Espectáculo de la Fábrica de Cultura del Jardín São Luís, por un lado, como actividad de contratación escolar y, por otro, como un espacio promotor de capital cultural. Al desarrollar el concepto de capital cultural y su incorporación por las actividades del Proyecto se analizó, también, la contribución del aumento del volumen de ese capital al literal de los participantes. La investigación estableció categorías de análisis para comprender la incorporación del capital cultural como forma de desarrollar habilidades y competencias definidas como importantes al letramento. Se pretende expandir las conclusiones que posibilitaron afirmar la hipótesis planteada durante la referida disertación: el Proyecto Espectáculo, del Programa Fábricas de Cultura, de la Secretaría de Cultura del Gobierno del Estado de São Paulo, puede contribuir a la superación de los déficit originarios del país, capital cultural de jóvenes estudiantes y, como consecuencia, promover mejoras en el grado de letra de los participantes.
\end{abstract}

PALABRAS CLAVE: Capital cultural; Alfabetización; Éxito escolar; Actividades culturales; Políticas públicas.

\section{INTRODUÇÃO}

Para compreender e registrar, de maneira eficaz, o resultado da dissertação de Mestrado Capital cultural e letramento: participantes do Programa Fábricas de Cultura em São Paulo (MONTEIRO, 2017), torna-se necessário desenvolver, brevemente, o caminho metodológico que possibilitou a análise dos resultados. Assim, este artigo compõe-se de três etapas (excetuando a introdução e as considerações finais), sendo a última o resultado da pesquisa: a análise das falas dos agentes, fornecidas por meio de um questionário socioeconômico e duas 
entrevistas não diretivas, construídas a partir de alguns conceitos, especialmente o do capital cultural e do letramento.

O registro dos resultados alcançados é importante para compreender-se a capacidade de atividades do contraturno escolar em ofertar um capital cultural que a escola não promove, mas que acaba sendo importante ao êxito do estudante. Assim, a referida pesquisa partiu da análise das falas de participantes de uma atividade cultural promovida pelo Programa Fábricas de Cultura, um projeto desenvolvido pela Secretaria Estadual de São Paulo, em parceria com a Organização Social para Cultura, POIESIS ${ }^{1}$.

Acredita-se que o objetivo da pesquisa foi alcançado de maneira satisfatória. Embora alguns questionamentos possam ser realizados a partir da pesquisa, o artigo centraliza a análise dos dados, que permite refletir a capacidade crítica da atividade como um espaço de letramento não escolarizado (ROJO, 2009), além de promotora de capital cultural.

A realização da pesquisa justificou-se pela assunção de uma crise na escola contemporânea. Assume-se que a desigualdade social e a incapacidade da escola em tratar estudantes das diferentes classes são fatores essenciais a esse cenário. Resultados como os do PISA 2015 (INEP, 2016) demonstram, por meio de dados quantitativos, o funcionamento do insucesso escolar. O aproveitamento dos estudantes brasileiros está muito abaixo do esperado e, segundo o próprio documento, o “[...] nível socioeconômico está associado com o desempenho dos estudantes nos testes cognitivos" (INEP, 2016, p. 239).

Para o desenvolvimento da pesquisa, foram alavancados dados sobre a instituição escolar, o sucesso escolar na visão de Pierre Bourdieu e a relação da escola com outras esferas sociais. Não foi a relação direta do estudante com a escola o recorte da pesquisa. Esta teve como objetivo compreender - a partir do reconhecimento da realidade social e educacional brasileira, empregando os conceitos de Bourdieu para isso - como as atividades de contraturno escolar se encaixam nesse cenário. Em uma sociedade em que a escola legitima a dominação e a hierarquização social por meio de uma estrutura tradicional (BOURDIEU, 1998a), questionase: Quais as possibilidades de uma atividade como o Projeto Espetáculo reverter essa lógica? Não se trata de propor uma solução, mas, sim, compreender quem são os participantes e até onde vai a possibilidade de acúmulo de capital cultural proporcionada por tais atividades e o desenvolvimento de habilidades típicas do letramento, que a escola não consegue alcançar, mas que são importantes para a vivência em diversas esferas sociais. 


\section{CAPITAL CULTURAL E LETRAMENTO}

Embora capital cultural e letramento sejam conceitos provenientes de autores distintos, com construções metodológicas próprias, certamente não são distantes. Durante a pesquisa, percebeu-se grande influência de Bernard Lahire nos teóricos do letramento. O texto, no qual o autor analisa o sucesso escolar nos meios populares (LAHIRE, 1997), detém os elementos que constituem a desigualdade de capital social e cultural, além da noção de herança cultural, socialização extraescolar, em especial a familiar.

A aproximação essencial entre os dois conceitos está no fato de que o "sucesso escolar" se define entre a função do distanciamento da cultura escolar com a cultura da família. Quanto mais distante a socialização familiar é da cultura escolar e erudita, da norma culta e da norma padrão, mais difícil é obter o sucesso escolar. A possibilidade de alcançar as habilidades exigidas à prática do letramento ocorre em função do distanciamento do letramento adquirido no meio familiar e o letramento exigido na escola. Quanto mais distante o uso da língua escrita e da leitura, mais complexo e difícil se torna, também, o sucesso escolar.

O capital cultural diz respeito ao conjunto de conhecimentos, de experiências e de vivências que pode ser revertido no mercado escolar. Desse modo, aquilo que o estudante detém, incorporado em seu habitus, e que pode beneficiá-lo para alcançar êxito na instituição escolar. O valor do capital cultural é, portanto, em essência, determinado pelo funcionamento do mercado escolar. Com isso, afirma-se que a escola classifica determinados bens culturais de acordo com a hierarquização presente no campo social.

Entretanto, na pesquisa, o objetivo não foi discorrer sobre o sucesso ou insucesso dos participantes do Projeto. Estabeleceu-se uma relação entre a aquisição de capital cultural e o letramento. Os teóricos do tema, frequentemente, estabelecem uma relação direta entre o letramento e o sucesso escolar. No ambiente familiar, o jovem interage, por exemplo, com textos em revistas, recebe e transmite informações escritas. $\mathrm{O}$ meio familiar não é espaço apenas do uso objetivo do letramento, como também o desenvolve, em diferentes medidas, para cada realidade e nas relações escolares. A família define-se como promotora da herança cultural, que é um elemento extraescolar, decisivo ao desenvolvimento do letramento e da capacidade em adquirir novos capitais culturais.

Dentre as duas formas de compreender o letramento, decidiu-se usar o enfoque dito "forte", que se expande às práticas sociais como construídas, dando-lhe a capacidade de reforçar 
ou questionar os valores estabelecidos (SOARES, 2006, p. 74). Portanto, na pesquisa, letrar não esteve reduzido ao uso mecânico na realidade cotidiana, mas, sim, à capacidade de compreender criticamente relações escritas e agir diante da própria realidade.

\section{PROCESSO DE PESQUISA}

Nesta seção, abordam-se a escolha do campo de pesquisa, os agentes envolvidos no Projeto Espetáculo, na Fábrica do Jardim São Luís, e os instrumentos de pesquisa, os quais abrangeram um questionário socioeconômico e duas entrevistas orais.

\subsection{A escolha do campo}

Para compreender melhor o objeto de análise da pesquisa, é importante levantar as variáveis, abordadas por Bourdieu (1998b), que contribuem para indicar o capital cultural dos estudantes. Assim, antes de tudo, registra-se o local de residência. Este, em relação à estrutura social, surge como um elemento central para a escolha do campo.

A própria definição dos locais para a construção das Fábricas de Cultura deu-se a partir de um esforço do Estado de São Paulo em identificar aqueles que mais necessitavam de oportunidades culturais e educativas. Para tanto, desenvolveu-se o Índice de Vulnerabilidade Juvenil, produzido pela Fundação Sistema Estadual de Análise de Dados (SEADE), com informações coletadas no ano de 2000 (SEADE, 2017).

Diversos dados que ajudam a compreender a realidade social da cidade de São Paulo, do Distrito do Jardim São Luís e da população estudada, elucidam, também, a relação do local de residência e a realidade social. Um exemplo é o Rendimento Nominal Médio Mensal das Pessoas Responsáveis pelos Domicílios Particulares Permanentes. Nos bairros centrais, a média figura entre $\mathrm{R} \$ 3.746,86$ e $\mathrm{R} \$ 5.576,78$. Um valor muito acima dos distritos considerados de grande vulnerabilidade, com faixa entre $\mathrm{R} \$ 447,04$ e $\mathrm{R} \$ 921,86$.

Nos dados referentes à escolarização dos jovens entre 15 e 17 anos, os distritos do grupo 5 (que apresentam maior vulnerabilidade juvenil) apresentam de 26,06\% a 41,30\% de jovens que não frequentam a escola, enquanto os distritos do grupo 1 (que apresentam menor vulnerabilidade juvenil e que estão nas regiões centrais) reúnem entre 7,52\% e 11,05\% de jovens nas mesmas condições. Nos distritos de maior vulnerabilidade, entre 40,05\% a 66,33\% 
dos jovens de 18 e 19 anos não concluíram o Ensino Fundamental, em 2000, enquanto, nos distritos centrais, esse percentual chega a, no máximo, 21,95\% (MONTEIRO, 2017).

Tendo em vista essa realidade, as Fábricas de Cultura foram desenvolvidas para oferecer cursos, bibliotecas, shows gratuitos, oficinas artísticas, dentre outras atividades que podem ser consideradas capitais culturais em estado objetivado (BOURDEIU, 1998b). Dentre as atividades, escolheu-se pesquisar o Projeto Espetáculo, um espaço que promove uma experiência coletiva de produção artística, em especial, cênica.

Segundo Bourdieu (1998a), a arte é um campo que se liga diretamente ao mercado escolar e ao conhecimento exigido pela escola, ainda que não seja conteúdo direto de avaliação. A instituição escolar acaba por legitimar determinadas formas artísticas, enquanto marginaliza outras. Nesse momento, o mercado escolar determina valor às obras de arte segundo a sua lógica, ou seja, entende como mais valioso aquele que se aproxima de sua linguagem e estrutura. Constrói-se uma hierarquia de formas, de gostos e de expressões que insere cada agente segundo a identidade que cada tipo de obra de arte lhe promove. Aqueles que se identificam com expressões artísticas voltadas à linguagem oral, por exemplo, e que não se expressam pela norma culta da língua, estão desenvolvendo um capital cultural sem tanto valor à escola. Essa expressão, embora seja potencialmente letradora, pelo seu distanciamento da escola, acaba por não produzir um conhecimento que lhes assegurará sucesso escolar.

\subsection{Os agentes}

O Projeto Espetáculo, na Fábrica do Jardim São Luís, conta com a participação de aproximadamente 60 jovens. Entretanto, para a realização da pesquisa, foi necessário fazer um recorte para alcançar menor grau de variação de idade e de homogeneidade na localidade de residência e no tipo de ensino. A partir da análise das variáveis, estabeleceu-se que os estudantes deveriam ter entre 14 e 21 anos, estudar em escolas públicas e residir na periferia, em especial, próximo à Fábrica.

Foram, portanto, oito os jovens escolhidos para participar da pesquisa: dois do sexo masculino e seis do sexo feminino. Uma estudante deixou a atividade no meio da realização do estudo. Embora não tenha sido possível a aplicação de todos os instrumentos de extração de dados, algumas informações referentes a ela foram contempladas e utilizadas, com grande valia. 
Além da variável "residência", a variável "tipo de ensino" também enquadra todos os participantes na mesma realidade. No cenário brasileiro, há uma tendência a compreender o ensino como dualista (ROMANELLI, 1986), com duas estruturas que promovem a educação escolar (pública e privada). Ambas necessitam transmitir os mesmos conteúdos, utilizam práticas pedagógicas semelhantes, preparam seus estudantes para as mesmas avaliações, que permitem a continuidade do estudo, detêm a mesma forma e estrutura; entretanto, seu público se distingue, não apenas pelo capital econômico, mas, especialmente, pelo capital cultural.

\subsection{Instrumentos de pesquisa}

Um levantamento das outras variáveis que compõem o capital cultural, observadas por Bourdieu em seus estudos, foi essencial para a construção do primeiro instrumento de pesquisa: um questionário socioeconômico sobre dados relativos a variáveis como categoria socioprofissional e escolaridade do pai e da mãe, proximidade com a leitura, participação de atividades sociais e artísticas, frequência de viagens, renda familiar, dentre outros.

A última parte do questionário versa sobre a motivação dos jovens em participar da atividade. Esta não se liga ao capital cultural do jovem, diretamente. Entretanto, Bourdieu (1998a) afirma que atividades culturais, como, nesse caso, as do Projeto Espetáculo podem atrair os estudantes que, em comparação àqueles de realidade semelhante, em função da origem social e familiar, possuem um capital cultural mais desenvolvido. A hipótese de que esses jovens têm um gosto diferenciado para artes em comparação a outros, inseridos no mesmo contexto social, foi confirmada nas respostas. Grande parte dos entrevistados demonstrou buscar bens culturais "raros" em sua realidade e expandir o conhecimento artístico.

Após a aplicação do questionário socioeconômico, realizaram-se duas entrevistas orais, uma no início das atividades e outra ao final. Ambas iguais e estipuladas a partir de informações acerca do tema central do Projeto - o "Amor nas Arcádias da Paulicéia" - e base para a realização da atividade. A questão apresentada sugeriu que se falasse sobre o que mais chamou atenção nos encontros do Projeto, discorrendo a partir das informações e dos materiais usados como referência para a construção da dramaturgia (MONTEIRO, 2017).

Devido a um intervalo reduzido entre as duas entrevistas, ambas se diferenciaram, não pela primeira evidenciar "menos capital cultural" e a segunda mais. Cada resposta dada pelos estudantes foi construída a partir das atividades - propostas naquele momento e não, 
necessariamente, o que foi citado na primeira voltou a ser citado, com mais complexidade, na segunda. Assim, os dados das entrevistas somaram-se para a inferência, não sendo realizada uma análise comparativa entre ambas.

Utilizou-se o método de categorias de análise para inferir os dados, estabelecendo-as a partir dos três temas presentes nas falas dos estudantes: a) amor; b) gênero; c) morte. Para cada categoria, utilizou-se um índice com objetivo de simbolizar o nível de aprofundamento do respectivo tema. Os índices foram definidos de 0 a 3 e se basearam na capacidade de compreender, descontruir seu senso-comum e associar o tema a diversos acontecimentos da atividade e fora dela.

O índice 0 representa que não houve qualquer menção ao tema durante a entrevista. Isso não significa que o estudante não sabia sobre ele ou não conseguiu expor seu conhecimento. Deve-se compreender que a pergunta foi feita deixando cada participante à vontade para construir sua fala de acordo com aquilo que lhe trouxe identificação.

O índice 1 representa apenas a citação, sem qualquer grau de aprofundamento. Quando o tema está representado pelo número 2, significa que houve uma compreensão mais detalhada, pois os agentes puderam perceber alguma relação entre o tema e as atividades propostas ou com as questões cotidianas. O último indicador, representado pelo número 3 , mostra que a fala do estudante foi preenchida por mais de uma análise do tema. Isso significa que ele o ampliou para um texto literário e um caso particular, ou que o desenvolveu a partir de uma notícia de jornal e de uma reflexão que desconstruiu uma noção sobre o tema, típica do senso-comum (definida como senso-comum pelo próprio agente da fala).

As experiências mais recorrentes, citadas nas entrevistas, que parecem influir diretamente a percepção sobre os temas categorizados são: leitura do Grande Sertão: Veredas, de Guimarães Rosa; notícia sobre o assassinato da transexual Dandara; e visita ao cemitério ao lado da Unidade Jardim São Luís. Além destes, também foi perceptível que alguns participantes não incluíam essas experiências ou as incluíam apontando relações próprias, cotidianas, da realidade que vivenciam.

\section{ANÁLISE DE DADOS}

Nesta seção, são analisados os dados gerados a partir do questionário socioeconômico aplicado junto aos participantes e da entrevista oral, a qual ocorreu em duas etapas distintas. 


\subsection{Questionário socioeconômico}

O questionário socioeconômico foi estruturado para inferir dados sobre: o capital institucionalizado dos pais (diplomas e certificados); o conhecimento de línguas estrangeiras; acesso, tempo disponível e contato com atividades artísticas e culturais; a renda familiar; a ocupação profissional; a ajuda para realizar as tarefas de casa; as motivações para participar do Projeto Espetáculo.

$\mathrm{Na}$ primeira parte, além da identificação de cada participante, procuraram-se dados sobre o capital econômico. As respostas dadas indicaram que apenas um entrevistado tem renda familiar de até $\mathrm{R} \$ 6.999,00$. Os outros cinco participantes que responderam à questão (dois deixaram em branco), afirmaram que a renda familiar não supera os $\mathrm{R} \$ 2.999,00$.

O trabalho partiu da concepção de que o capital econômico interfere no cultural; entretanto, de forma alguma o define. O capital cultural pertence a um campo próprio. Assim, a hierarquia de valores e o espaço ocupado no campo social estabelecem e viabilizam oportunidades próprias desse campo. Correlacionando os dados do questionário com outros índices, e tendo em vista tal distinção entre os campos, percebe-se que os agentes não detêm as rendas mais baixas do distrito, mas são inferiores às dos bairros mais centrais.

As outras partes do questionário versam sobre o capital cultural em seus múltiplos estados. Assim, é necessário definir quais são eles e as circunstâncias em que o capital cultural está disposto na estrutura social. Em princípio, tem-se o estado incorporado, o mais comum, e diz respeito ao próprio habitus. Sua aquisição ocorre de forma dissimulada e inconsciente, sempre como uma expansão daquilo que se define pela herança cultural. Bourdieu (1998b, p. 74) o traduz como "[...] um ter que se tornou ser, uma propriedade que se tornou parte integrante da pessoa".

A relação com o tempo é imprescindível para o aumento do seu volume, a partir daquele já agregado nas socializações familiares. Para inculcá-lo, certo tempo deve ser investido. Uma das questões que se decidiu analisar, no questionário, foi, portanto, como esse tempo é gasto, quais atividades têm potencial para agregar capital cultural e, também, quais ações realizadas pelos participantes podem obter efeitos letradores.

Apenas um participante afirmou ocupar seu tempo com atividades profissionais. Entretanto, os dados demonstraram que a questão do tempo não se reduz ao fato de ter ou não ter um trabalho para poder ou não "gastar" o tempo livre em atividades culturais. Nesse sentido, 
a análise do questionário tentou compreender, também, relações entre as atividades realizadas e as possibilidades que estas geram no capital cultural e no letramento.

A maneira como os estudantes utilizam o tempo disponível pôde ser observada nas respostas dadas ao questionário; contudo, estipular o capital cultural em estado incorporado, quantificá-lo, não foi possível. Trata-se de um elemento subjetivo, agregado ao corpo, ao habitus. As falas das entrevistas podem alertar para algumas conclusões, sem defini-las por completo, e os dados do questionário informam as possibilidades de inculcação desse capital, dentro da realidade de cada agente. Tem-se, por exemplo, que o único estudante que afirmou trabalhar vem da família de maior renda, participa de mais atividades culturais que os outros entrevistados e diz, inclusive, participar do Projeto Espetáculo por "ter tempo livre".

O segundo estado analisado no questionário é o institucionalizado. Este diz respeito a diplomas e certificados, ou qualquer materialização determinada por um valor legal e jurídico. A compreensão da herança cultural de cada participante passa obrigatoriamente pelo capital institucionalizado dos pais. Nesse sentido, o questionário abordou também a profissão do pai e da mãe, bem como se são ou não alfabetizados. Os dados evidenciaram a falta de diplomas de nível superior na grande maioria dos casos. Todavia, entre os oito entrevistados, apenas uma mãe não é alfabetizada. Duas mães e um pai têm nível superior, os três de famílias distintas. Dois entrevistados têm pais ausentes.

A categoria socioprofissional dos pais representa o nível de letramento possível na socialização familiar e o capital linguístico ofertado pela herança cultural. As ocupações variam muito entre os pesquisados; entretanto, pode-se afirmar que, dos participantes do Projeto, apenas duas mães se ocupam de atividades profissionais que utilizam fortemente as habilidades de letramento (uma professora e uma psicóloga).

O último estado é o objetivado. Este é produto da ação histórica, ativo, atuante e, embora tenha sua força no campo simbólico das lutas, atua de maneira material. Diz respeito, em essência, ao campo da produção cultural, podendo agir ou não à conservação da estrutura social. O Projeto Espetáculo é um capital cultural em seu estado objetivado; desse modo, a presente pesquisa teve, como propósito, compreender se ele tem a capacidade de trazer à incorporação, de inculcar os conhecimentos e as vivências artísticas e contribuir para o letramento dos participantes.

As obras artísticas, em toda a sua capacidade multissemiótica, são definidas como um capital no estado objetivado. Entretanto, no que se refere à leitura e à escrita, há também o 
capital linguístico (BOURDIEU; PASSERON, 2012), que é revertido no mercado escolar. A pesquisa não se deteve nesse conceito; entretanto, algumas perguntas se relacionam diretamente ao manejo da língua e ao contato com a escrita, por exemplo, o conhecimento de uma segunda língua. As respostas informam que dois participantes detêm conhecimento sobre a língua inglesa e espanhola, sendo um estudante apenas sobre a inglesa. A elaboração do questionário não objetivou saber exatamente qual o grau de conhecimento de cada estudante nos idiomas mencionados. O que se torna importante ao resultado é a conclusão de que cinco dos oito participantes consideram não saber o suficiente para assinalar que detêm conhecimento sobre determinada língua estrangeira.

$\mathrm{Na}$ análise dos dados sobre a leitura, pôde-se inferir que apenas as respostas da estudante que tem o pai com Ensino Superior e a mãe formada até o Ensino Médio evidenciaram uma leitura frequente. A posse de livros e materiais escritos no ambiente familiar é de extrema importância; no entanto, o hábito da leitura, por si só, não ocasiona a identificação com a escola. A instituição escolar determina uma literatura específica que deve ser compreendida pelos estudantes. Assim, certas leituras, ainda que contribuam ao letramento e sejam um bem cultural, podem não ter valor no mercado escolar.

A audiência desses jovens dada à televisão - que para muitos é considerada um impeditivo ao estímulo da leitura -, não se mostrou muito popular. Em geral, os participantes não afirmaram assisti-la, e três deles nunca a utilizam.

A possibilidade de viagens plurais, contatos e experiências diversas, também contribuem para o acúmulo de capital cultural. Apenas um estudante afirmou realizar mais de dez viagens por ano e, em contrapartida, um dos entrevistados viajou uma única vez no mesmo período. Apenas dois entrevistados já viajaram sem a família. Aquele que tem uma ocupação profissional é o que mais viaja, lê com frequência e participa de mais atividades culturais em comparação aos outros pesquisados. Talvez a questão econômica, uma vez que é o jovem com maior renda mensal declarada e o capital social acumulado nas atividades profissionais, influencie de maneira decisiva a incorporação de capital cultural.

A frequência ao teatro, cinema e concertos representa o acesso ao capital cultural em seu estado objetivado, ocasiona o letramento dos jovens e foi abarcada pela pesquisa. "O contato com expressões artísticas fornece meios para desenvolver o capital cultural e é, também, um uso importante da linguagem oral, da imagem, som e leitura, em dimensões social e individual" (MONTEIRO, 2017, p. 91). Em se tratando dos participantes da pesquisa (oito ao 
todo), três deles comparecem a intervenções artísticas semanalmente, quatro vão mensalmente e apenas um comparece anualmente. Seis participantes ocasionalmente vão a exposições, e cinco deles também vão a shows. A participante que abandonou o Projeto Espetáculo relatou, em suas respostas, pouca participação em atividades culturais.

Admite-se que cada jovem tem determinada capacidade para compreender certas intervenções artísticas de acordo com a linguagem e as suas formas. A mera frequência não representa um real acesso àquilo de que a escola espera. $\mathrm{O}$ processo de aquisição de conhecimento e de aumento de volume do capital cultural tem ponto de partida na herança cultural, mas é contínuo e tramita, também, por uma restrição que surge no campo econômico e impede determinados acessos a bens culturais. Assim, percebe-se que não há dado que, sozinho, seja capaz de definir os entrevistados em um espaço delimitado no campo social. Torna-se perceptível que a compreensão se dá entre as diversas variáveis e os diferentes fatores como conjunto. Estes compõem, transversalmente, as possibilidades sobre o capital cultural dos participantes e as de letramento.

Os dados permitem afirmar que os participantes do Projeto já detêm alguma motivação pelo campo artístico e que a participação no Programa Fábricas de Cultura se justifica em um interesse anterior ao Projeto, em agregar capital cultural. Um exemplo des sa conclusão está no fato de que, dentre os oito entrevistados, cinco participaram do Projeto por decisão pessoal e três por influência dos pais. Destes últimos, o fato de um deles ter o pai com nível superior e outro ter a mãe com a mesma escolaridade reforça a importância do capital institucionalizado como parte de uma herança cultural, que é ponto de partida à aquisição de novos capitais culturais. Além disso, a maioria dos participantes respondeu que a participação no Projeto Espetáculo é importante para o seguimento de suas vidas profissionais. Seis estudantes assinalaram o gosto pelas artes como fator para participar da atividade. A partir desses dados, concluiu-se que existe uma falta de identificação com a escola, por parte desses estudantes, que os fazem projetar um futuro a partir das Fábricas de Cultura, um espaço que lhes traz identificação.

Cada realidade, em outras palavras, cada habitus dotado de um capital social, cultural peculiar e influenciado pelas possibilidades econômicas, impede que esses estudantes consigam tal aperfeiçoamento em espaços que não estejam alocados em uma política pública para a educação e a arte, como o Projeto Espetáculo. Certamente, existe, em cada periferia, em cada distrito considerado de classe desprivilegiada, um número razoável de estudantes que tem, em 
comparação aos outros da mesma realidade, um interesse e uma vontade distintos de entender e utilizar a arte para o sucesso escolar, profissional e pessoal.

\subsection{Entrevistas}

$\mathrm{Na}$ dissertação em foco, a análise da entrevista oral ocorreu em duas etapas distintas. Como o número de participantes é pequeno, e pelo fato de as entrevistas não serem extensas, a primeira parte analisou cada estudante, somando as falas da primeira e segunda entrevista. A segunda etapa deteve-se na reflexão do conjunto das falas, a partir da aparição de cada tema. Antes de iniciar o registro das conclusões sobre as entrevistas, vale registrar que a grande maioria dos pesquisados já participava das atividades em anos anteriores. Assim, entende-se que esses jovens já estavam sendo letrados, acumulando capital cultural a partir do Projeto.

O tema "amor" foi o que mais apareceu entre os definidos como categorias de análise. Geralmente, com uma ampliação de significado e de desconstrução da noção senso-comum. Cinco participantes, na primeira entrevista, relataram algo semelhante ao citado, sobre a desconstrução do tema. Tratou-se de uma ampliação de conhecimentos que fugiram da noção burguesa de amor romântico. O amor, então, foi visto de maneira inteiramente nova em seus repertórios. Uma desnaturalização que demonstra a crítica à forma propagada de maneira banal, por programas de televisão e pela cultura de massas em geral.

Ao pensar-se a lógica do capital cultural, deve-se notar que a desconstrução do tema demonstra que houve, por meio da atividade, a elaboração de um conhecimento mais valorizado no campo cultural, pois a ampliação do conceito remete a novas formas de interpretação das vivências. $\mathrm{O}$ amor talvez seja um elemento importante da arte que, visto de muitas formas, no desenrolar histórico, proporciona uma capacidade diferenciada de compreensão ou, ao menos, não limita um entendimento vazio que se reduz ao casamento da telenovela. Um olhar crítico da cultura massificada é algo pouco explorado na escola; entretanto, pode propiciar conhecimentos importantes ao sucesso escolar.

Esse olhar não necessariamente se encerra em possibilidades novas no mercado escolar. Ele aumenta o aprofundamento sobre certas relações sociais, como nas palavras do participante intitulado como G: "Porque a gente fala muito sobre o sofrimento das pessoas hoje em dia [..], realmente é a nossa realidade, de quem vive na periferia, sabe que é difícil e que a gente sempre vai ter dificuldades". Trata-se de uma visão mais ampla do próprio contexto social. Um 
estranhamento da dominação e da hierarquia social importantes para que cada estudante consiga sair do papel de sujeito estruturado para agente estruturante.

O participante $\mathrm{C}$, por exemplo, relata estar descobrindo "[...] coisas que acontecem no dia a dia e a gente também, a gente nem passa pela nossa cabeça que acontece". A participante completa a fala dizendo como é importante tratar tais descobertas com outros participantes. G, no mesmo sentido, afirma que "[...] é bom trabalhar isso em grupo, e principalmente em grupos de pessoas com a nossa idade, que pensa mais ou menos igual". Aqui é possível compreender que o capital social desses estudantes também é desenvolvido de maneira a fazê-los compreender a realidade social pelo conhecimento da realidade individual. No Projeto Espetáculo, além de os participantes interagirem entre si, também conheceram profissionais que transmitiram experiências e conhecimentos importantes ao aumento do capital social.

Os estudantes que não relataram a questão do amor na entrevista discorreram profundamente sobre a questão do gênero, a partir da leitura de Grande Sertão: Veredas, relacionando-o a aspectos do cotidiano e das relações sociais, bem como ao assassinato da transexual Dandara.

Fica perceptível que cada participante discorreu sobre aquilo que lhe traz identificação. Assim, o fato de este ou aquele participante não ter citado um tema específico, não influencia em nada o grau de conhecimento adquirido. Deve-se relembrar que a entrevista não foi diretiva e não houve um incitamento para que os estudantes perpassassem por determinado tema em suas falas.

A capacidade de um Projeto interferir positivamente na desconstrução do preconceito de gênero, por meio da análise de acontecimentos cotidianos e da literatura clássica, causa dois efeitos. Em primeiro lugar, traz uma identificação àqueles que, embora ainda jovens, já se compreendem incorporando um gênero distinto, tido como "incomum" pelo discurso intolerante. Assim, se a escola não é um espaço confortável para esses agentes, o Projeto Espetáculo demonstrou, durante a pesquisa, que consegue sê-lo. Em segundo lugar, essas discussões são típicas de um discurso acadêmico e atrai, de certa forma e em certa medida, estudantes do Ensino Médio àquilo que o Ensino Superior tem discutido.

O último tema avaliado, "morte", dentre as três categorias de análise, é o que menos surgiu. Durante a segunda entrevista, foi possível compreender que a visita ao cemitério incitou a discussão para a construção da peça, ocorrendo pouco antes da realização da segunda entrevista; portanto, só esteve presente nela. Interessante notar que os mesmos agentes que 
aprofundaram o tema gênero discorreram, também, com grande complexidade, acerca do tema morte.

Dentre outros possíveis temas que surgiram nas falas, tais como quilombo, utopia e arcádia, não há muito a se discutir. O que deve ser registrado é o fato de que "arcádia" foi apresentado na proposta inicial do Projeto, para 2017, como central à construção da peça. As menções a esses três elementos mostram, ao menos, uma ampliação de vocabulário e, possivelmente, uma incorporação de novos capitais culturais, essenciais ao processo de letramento desses jovens.

Os três temas, em especial "morte" e "gênero", foram tratados com base no livro Grande Sertão: Veredas. Pode-se considerá-lo, inicialmente, como um capital cultural em seu estado objetivado que foi incorporado, em distintos graus, pelos participantes. Embora tenha sido perceptível que estudantes não leram o livro completo, estes compreendiam a história, as questões discutidas nela, os personagens e o enredo. Assim, na primeira entrevista, seis participantes fizeram, ao menos, uma menção ao "amor"; e cinco, ao "gênero". Já, na segunda, cinco participantes contemplaram o "amor", enquanto quatro discutiram "gênero".

A categoria "amor" foi a que mais recebeu o índice 3. Na primeira etapa, ela foi classificada com o índice 3 em cinco falas e, na segunda etapa, em três. Quanto a categoria "gênero", quatro participantes chegaram ao índice 3 na primeira entrevista, e apenas um na segunda. É interessante notar que todos os participantes, em ao menos uma das entrevistas, receberam o índice superior 3 para algum tema.

A categoria "morte", por ter sido objeto de discussão posteriormente à primeira entrevista, foi contemplada por apenas três agentes (e apenas na segunda entrevista), sendo dois deles com índice superior de aprofundamento (3).

\section{CONSIDERAÇÕES FINAIS}

A realidade educacional brasileira está cada vez mais obsoleta e distante de alcançar os objetivos de letramento necessários às demandas sociais de uma sociedade grafocêntrica. $\mathrm{O}$ distanciamento da escola, das famílias e da comunidade, a incapacidade de incorporar práticas de letramentos locais e multissemióticos, o ensino dualista, dentre outras variáveis, reforçam uma desigualdade nos campos social e cultural. 
As falas dos participantes evidenciam que a atividade promovida pelas Fábricas de Cultura oferta um conhecimento distinto daquele transmitido, tradicionalmente, pela escola. Compreendemos, na pesquisa, como um real aumento de capital cultural contribui, em algum grau, à superação de déficits do capital cultural iniciado pela herança cultural e perpetuado na incapacidade escolar de receber estudantes de distintas realidades. Paralelamente a isso, foi possível constatar que o acesso da periferia de São Paulo a bens culturais, escassos nessas regiões, tem em políticas públicas, como o Projeto Espetáculo, um aumento importante.

Entretanto, essas atividades não excluem o compromisso de a escola em apreender outras formas de contato com a linguagem. A escola deve se atentar a novas formas de uso da língua, da escrita e da leitura, que podem favorecer o processo de letramento, sobretudo na rede pública de ensino. Aproximar as práticas de letramento não escolarizadas, locais e multissemióticas é uma oportunidade de reestruturar a forma como o mercado escolar lida com as expressões culturais marginalizadas.

Também há de se pensar nas novas ferramentas tecnológicas, a formação espontânea de expressões culturais na periferia, dentre outras que, geralmente, são vistas como práticas que não valorizam o letramento, portanto um capital cultural de baixo valor. A intervenção do Estado é importante para suprir determinadas carências; contudo, mais ainda para, em parceria com a sociedade civil, "atualizar" a escola.

Paralelamente a isso, atividades como o Projeto Espetáculo têm papel importante para a formação de um novo capital cultural, fornecido aos participantes, aumentando o grau de letramento. Ficou evidente que todos os entrevistados ampliaram o conhecimento que detinham acerca dos temas propostos. A partir daquilo que mais lhes chamou atenção, os estudantes desenvolveram suas falas, demonstrando um conhecimento estimulado pela atividade. $O$ índice 3, na análise da entrevista, representa o maior nível de aprofundamento. Todos os participantes o receberam em, ao menos, um dos temas analisados. Assim, os dados obtidos evidenciam o potencial do Projeto Espetáculo como prática de letramento não escolarizada, um capital cultural objetivado, ofertado a jovens residentes em regiões de maior vulnerabilidade social, que promove a incorporação de bens culturais, essenciais ao sucesso escolar. A pesquisa aponta a diferenciação e a riqueza que um trabalho nos moldes da Fábrica de Cultura poderia proporcionar se ela estivesse inserida nas escolas públicas brasileiras. O salto cultural propiciado para crianças e jovens seria tão enriquecedor que faria a diferença nos resultados escolares gerais. 


\section{REFERÊNCIAS}

BOURDIEU, Pierre. A escola conservadora: as desigualdades frente à escola e a cultura. In: NOGUEIRA, Maria Alice; CATANI, Afrânio (orgs.). Escritos de educação. 6. ed. Petrópolis, RJ: Vozes, 1998a. p. 39-64.

BOURDIEU, Pierre. Os três Estados do capital cultural. In: NOGUEIRA, Maria Alice; CATANI, Afrânio (orgs.). Escritos de educação. 6. ed. Petrópolis, RJ: Vozes, 1998b. p. 7179.

BOURDIEU, Pierre; PASSERON, Jean-Claude. A reprodução: elementos para uma teoria do sistema de ensino. 5. ed. Petrópolis, RJ: Vozes, 2012.

INEP. Instituto Nacional de Estudos e Pesquisas Educacionais Anísio Teixeira. Brasil no PISA 2015: análises e reflexões sobre o desempenho dos estudantes brasileiros. São Paulo: Fundação Santillana, 2016. Disponível em: http://download.inep.gov.br/acoes_internacionai s/pisa/resultados/2015/pisa2015_completo_final_baixa.pdf. Acesso em: 20 out. 2017.

LAHIRE, Bernard. Sucesso escolar nos meios populares: as razões do improvável. São Paulo: Editora Ática, 1997.

MONTEIRO, Heloisa Marcassa. Capital cultural e letramento: participantes do Programa Fábricas de Cultura em São Paulo. Orientadora: Leda Maria de Oliveira Rodrigues. 2017. Dissertação (Mestrado em Educação: História, Política, Sociedade) - Pontifícia Universidade Católica de São Paulo, São Paulo, 2017.

ROJO, Roxane. Letramentos múltiplos, escola e inclusão social. São Paulo: Parábola Editorial, 2009.

ROMANELLI, Otaíza de Oliveira. História da educação no Brasil (1930/1973). 8. ed. Petrópolis: Editora Vozes, 1986.

SEADE. Evolução do IVJ 2000/2005. São Paulo, mai. 2007. Disponível em:

http://produtos.seade.gov.br/produtos/ivj/ivj_2000_05.pdf. Acesso em: 12 abr. 2017.

SOARES, Magda. Letramento: um tema em três gêneros. 2. ed. Belo Horizonte: Autêntica, 2006.

\section{NOTA}

${ }^{1}$ POIESIS. Disponível em: http://www.poiesis.org.br/new/poiesis/quem-somos.php. Acesso em: 12 abr. 2017.

Enviado em: 07/02/2019

Aprovado em: 03/08/2019 